\title{
VIDA COMO "ESTADO DE ALMA", AMIZADE À VIRTUDE UMA HOMENAGEM AO NOSSO MESTRE PROF. DR. MARCELO PIMENTA MARQUES
}

\author{
Maria Dulce Reis*
}

\begin{abstract}
RESUMO: O presente artigo faz uma homenagem ao professor Marcelo Pimenta Marques, ressaltando seu caráter como parte de seu legado a seus alunos e amigos. Destaca, na filosofia platônica, as concepções de virtude e vício, vida e morte "na" psykhế, como "estados de alma" conquistados segundo o grau de educação e amizade dos três gêneros da alma (tò logistikón, tò thymoeidés, tò epithymètikón), de autoconhecimento e conhecimento dos diferentes graus de Ser. Tal leitura reafirma a defesa de nossa tese de doutoramento que aponta a teoria da alma triádica como base da teoria ético-política de Platão, presentes sobretudo nos diálogos República e Leis.
\end{abstract}

PALAVRAS-CHAVE: Platão; Filosofia Antiga; ética; alma; virtude.

\section{LIFE AS "STATE OF SOUL”, FRIENDSHIP OF VIRTUE}

\begin{abstract}
This paper homages Professor Marcelo Pimenta Marques, exalting the character as part of his legacy to students and friends. In Plato's philosophy, the conceptions of virtue and vice, life and death "in" the psykhe, as "states of soul" conquered according to the degree of education and friendship of the three genders of the soul (to logistikon, to thymoeides, to epithymettikon), of self-knowledge and knowledge of the different degrees of Being. This angle reaffirms the defense of our doctoral thesis, pointing the triadic soul theory as the basis of Plato's ethical-political theory, present mainly in the dialogues Republic and Laws.
\end{abstract}

KEYWORDS: Plato; Ancient Philosophy; ethics; soul; virtue.

\section{Preâmbulo}

$\boldsymbol{\zeta}$ Vamos continuar essa conversa", essa foi a dedicatória do prof. Marcelo Marques a mim, no exemplar de seu livro lançado em 2006, ano da conclusão de minha tese de doutorado, orientada por ele e defendida no início de 2007. Acredito que fui sua primeira
$*$ Doutora
em Filosofia,
Universidade

Federal de Minas

Gerais. Professora

de Filosofia

Antiga, Pontifícia

Universidade Católica

de Minas Gerais.

mariadulcereis@

pucminas.br 
orientanda de doutoramento. Essa foi, também, a constante postura de Marcelo diante de seus orientandos e inúmeros alunos: a de estímulo ao debate filosófico, a de respeito aos alunos e ao exercício da Filosofia, a de não colocar um ponto final em um diálogo, bem como na interpretação de algum conceito da filosofia platônica. Um interlocutor "de peso", referência para nós, seus orientandos, esperávamos sempre por seu "feedback" quanto ao que tínhamos escrito ou pensado a respeito da filosofia de Platão. Privilégio tivemos, portanto, seus alunos e orientandos, por tê-lo tido como referência no conhecimento da Filosofia Antiga, como interlocutor em nossos estudos e como amigo, pois essa era também a sua postura, a de estar disponível para nos ouvir, trocar ideias, estimular, dar oportunidades, convidar. Assim, recebi sempre com muita honra seus convites para participação em congressos, "bancas de defesa" e para ministrar aulas. Quando fui chamada a ministrar a disciplina de Filosofia Antiga na PUC Minas (a partir do ano de 2015), compartilhamos isso como a conclusão de um ciclo de trabalho que estivemos desenvolvendo há anos. E somente hoje, como professora, entendo o que então chamei de excesso de liberdade, que me foi dada por Marcelo no decorrer da elaboração de minha tese. Importava a ele que a tese fosse do aluno, de seu autor. Essa autonomia dada ao aluno é sinal de confiança e condição para que uma tese seja, de fato, original.

Hoje estamos reunidos para homenageá-lo, para agradecer-lhe e para ressaltar o seu legado. E gostaria de destacar aqui que Marcelo nos legou não só sua obra, sua produção acadêmica, seu trabalho como professor e orientador. Ele nos legou as suas atitudes, o seu caráter. Pois seu trabalho e suas atitudes já nos mostravam, e continuam nos revelando, uma face de sua "alma" (tradução corrente para o termo psykhêe), seu caráter virtuoso. Ao ministrar as minhas aulas de Filosofia Antiga, agora sem a sua presença, tornou-se gritante, para mim, o quanto recebi dele: a formação, a influência, o exemplo, exemplo de trabalho e de alma. Presto a ele, aqui, sincera homenagem e profundo sentimento de gratidão.

O que nossa cultura tem a dizer sobre morte e vida? Há cerca de quinze anos atrás, Marcelo acompanhava meus estudos sobre a alma em Platão, época da "seleção" para o doutorado. Foi quando ele externou a mim que nós, ocidentais, estamos muito pouco preparados para o tema da morte, no sentido de que nossa cultura não costuma debater a respeito, não encara de frente essa realidade humana da mesma maneira que o fez o Sócrates platônico da Apologia, do Críton e do Fédon. Assim, quanto ao tema da morte, no decorrer de suas aulas e orientações, Marcelo o enfrentava como aos demais temas da filosofia platônica: com vigor, inteligência e sensibilidade. Continuo concordando com ele, pois agora que estamos diante de sua ida, nossa posição é a da fragilidade humana, a da dificuldade de falar a respeito desse tema. Proponho, então, reconhecermos a herança de Marcelo para todos nós, à qual me referi acima e, por meio dela, pensarmos sobre a relação entre morte e vida "na" alma humana - e não "da" alma.

Não tenho a menor pretensão de decifrar a alma de nosso mestre (e isso seria impossível). Minha intenção é a de reavivar aqui o seu legado: seu trabalho e seu caráter, que revelam muito da vivacidade de sua alma. Esse estado de "saúde da alma" evidenciou-se em suas pesquisas, seus livros, seus artigos, suas comunicações, suas aulas, suas orientações, 
em suas marcas intelectuais e afetivas. Amigo da sabedoria, curioso, dinâmico, ele não se reconhecia como um paradigma de Filósofo. Contudo, os temas por ele privilegiados em suas pesquisas, como o da alteridade, o da imagem, o da alma humana, dentre outros, nos revelam a agudeza de seu pensar filosófico, sua "natureza filosófica", sua alma sensível. O modo de ser de Marcelo faz parte de seu precioso legado e revela a riqueza de sua alma.

\section{VIDA COMO "ESTADO DE ALMA"}

O que a filosofia de Platão tem a nos dizer sobre vida e morte? Provoquemos nossas almas à reflexão. Em diálogos de maturidade e velhice, ao entrelaçar psicologia, ética e política, valendo-se de uma teorização sobre a natureza e a formação da psykhế para compreender as ações humanas e propor paradigmas de regimes políticos, Platão aborda várias espécies de morte. E várias espécies de amizade. Isso porque demonstra haver várias espécies de "estados de alma" passíveis de serem constituídos na unidade "corpo-alma" humana. Tratemos disso agora, "chamando Platão" para acudir nosso não-saber e dor, assim como para fundamentar a presente afirmação de que foi a conquista da virtude e a constante escolha pela "saúde da alma" - por manifestações de vida e pela mais pura amizade - que Marcelo realizou e que nos legou.

Que há uma unidade "corpo-alma" no homem vivo, carente de formação e educação, Platão sustenta desde diálogos de maturidade como no Fédon e na República, até em diálogos tardios, como no Timeu e nas Leis. Detalhamos tal unidade comum, sua natureza e possibilidades de formação, em vários trabalhos anteriores. ${ }^{2}$ Aqui desejamos destacar a importância, dada por Platão, à devida educação dessa unidade - alimentando-se com correta medida o corpo e os três gêneros da alma (o apetitivo/tò epithymétikón, o irascível/ tò thymoeidés, o racional/tò logistikón - para que se configure o estado de "virtude" no ser humano, isto é, para que ele se encontre em seu "melhor estado" e, assim, na posse das condições psicofísicas para guiar suas ações na vida prática. A ausência da devida educação dos mesmos gera estados de "vício", numa gradação que pode culminar com uma disposição interna da alma que beira a "morte psíquica", o estado de injustiça interna, de "escravidão

\footnotetext{
${ }^{1}$ Utilizo o termo "alma" como tradução para o termo psykhế na Filosofia Antiga, na falta de melhor termo em português, significando, em Platão, princípio de movimento e vida (o que constitui sua essência, definição e natureza, conforme Fedro 245c-e), estruturação triádica de princípios de ação no homem vivo: o racional, o irascível, o apetitivo (conforme República IV). Refiro-me a "estados de alma" como estados (pathémata) do todo da alma triádica, englobando suas capacidades cognitivas, emocionais e de ação, que irão variar conforme sua formação e educação. A alma humana é referida como "potência" tanto na República 437a-b como no Fedro 270c-d, capaz de afetar e de sofrer afecções. ${ }^{2}$ Ver Reis, 2000; 2007a; 2007b. Quanto à teoria da alma triádica, também interpretada como a teoria da tripartição da alma postulada na República IV, ver as referências bibliográficas presentes em Reis, 2009; 2010 e as indicações bibliográficas ao final deste artigo.
} 
de si mesmo", quando a alma vive em função da satisfação de seu elemento insaciável, o apetitivo, então mal direcionado. ${ }^{3}$

Dependendo do tipo de desejo construído no interior da alma - o apetite "de algo", ou seja, de algo então considerado "bom" (República 438a-b) - dependendo do tipo de amizade que essa estruturação da alma cultiva, a unidade "corpo-alma" pode caminhar da extrema pobreza à extrema riqueza, da escravidão de si (e do outro, da vida política) à autarquia, à conquista da liberdade de autonomia. Alimentar cada gênero da alma com o que lhe é devido, para Platão, é fundamental para a conquista da virtude. Se isso não ocorre, a alma possuirá um estado de injustiça, de vício. Destaquemos aqui a conquista da posse da virtude da justiça na psykhế como estado de unidade entre elementos diferentes, então em uma relação interna de amizade:

O verdadeiro é que a justiça é qualquer coisa deste modo, ao que parece, exceto que não diz respeito à atividade externa do homem, mas à interna, verdadeiramente sobre ele mesmo e sobre as coisas dele mesmo, sem consentir que cada um nele faça coisas diferentes, nem que os gêneros na alma façam muitas coisas umas pelas outras, mas, essencialmente, estabelecendo bem as coisas familiares, governando ele próprio a ele mesmo e ordenando-se, tornando-se amigo de si mesmo, tendo reunido harmoniosamente os que são três, exatamente como se fossem três termos numa proporção musical, o mais baixo, o mais alto e o intermédio, e outros quaisquer que acaso existam no meio, todos eles ligando e fazendo, de muitos, um, temperante e harmonioso - assim, enfim, agir (se é que ele em algo aja) a respeito da aquisição de riquezas, ou dos cuidados com o corpo, ou de política, ou de contratos particulares, considerando em todos esses casos e chamando justa e também bela à ação que salvaria e completaria isso que ele possui, e considerando sabedoria a ciência que preside a esta atividade, e denominando injusta a ação que desata [esses passos], e, ignorância, a opinião que preside essa ação injusta. (República 443c-d, grifo nosso) ${ }^{4}$

Nesse contexto, a virtude, em Platão, não deve ser vista como propriedade de uma determinada parte da alma, e sim deve-se reconhecer que os vários estados de virtude da alma correspondem a modos de relação saudável entre os três gêneros da psykehé em interrelação constante. Por exemplo, a temperança não é a virtude "do" apetitivo, e sim um modo de relação harmoniosa "entre" apetitivo, irascível e racional. Essa gradação possível de "estados

\footnotetext{
${ }^{3} \mathrm{Na}$ República IV-VII, a educação da unidade corpo-alma triádica vai ocorrer pela ginástica, pela arte das Musas, pelas ciências da época e pela dialética. Em Leis VII, encontram-se as etapas da educação da gestação à velhice, visando ao direcionamento dessa unidade para a virtude.

${ }^{4}$ Tradução de Jacyntho Lins Brandão para a dissertação de Reis, 2000; 2009. Vale notarmos que semelhante concepção de justiça se encontra subentendida na passagem das Leis em que um verdadeiro juiz é referido como aquele que torna os diferentes, amigos, aquele que promove uma verdadeira amizade entre as partes, a união e a paz no todo (Leis 627c s.).
} 
da alma”, entre saúde e doença, virtude e vício, vida e morte está presente na análise da alma dos governantes na República VIII-IX, no caminho de educação da alma do guardião contido no "diagrama da linha" e no "mito da caverna" (livros VI-VII), em passagens sobre a alma humana no Timeu, ${ }^{5}$ bem como nas argumentações das Leis sobre a educação da alma, sobre injustiça e dano, o caráter e o modo de agir, o diagnóstico e a cura da alma dos criminosos. Tal extensão, rigor e profundidade da psicologia platônica, que se mostra como base de sua teoria ético-política, nos permite inferir que "morte", para Platão, é um "estado de alma" do homem vivo. E "vida", o estado de "vitalidade plena" do ser humano, equivalente à posse, pela alma, de uma disposição virtuosa, de um modo de relação saudável entre os seus três gêneros distintos, o suficiente para que tal indivíduo aja com virtude na vida ético-política. Não são opiniões, ou afecções, ou determinados desejos que, isolados, conduzem à ação. $\mathrm{Na}$ filosofia de Platão - o que se encontra também na ética aristotélica - é o todo da alma em unidade com o corpo e na relação com o mundo e com os outros homens, que gera o agir humano e, por isso, as ações revelam as condições que a alma possui, isto é, o seu caráter.

Nos livros VIII e IX da República, tendo já defendido a psykhé como unidade triádica no livro IV, Platão diferencia o "amigo do saber", o "amigo do ganho", o "amigo da igualdade", o "amigo do poder", o "amigo dos prazeres". O arranjo interno entre o racional, o irascível e o apetitivo, vai configurar, de modo diferente, a alma do filósofo, a alma do timocrata, a alma do oligarca, a alma do democrata, a alma do tirano. O timocrata é amigo do poder, das honras, pois nele governa o gênero irascível da alma. O oligarca é amigo das riquezas, de determinados interesses, assim sua alma vive um conflito entre os gêneros racional e apetitivo. O democrata é amigo da igualdade pelo que é igual e pelo que é desigual, não distingue apetites bons e maus, portanto sua alma vive um conflito entre os gêneros irascível e apetitivo, entre os sentimentos de temor, respeito, vergonha e as demandas por prazer do insaciável gênero apetitivo (560a-561c). O tirano é amigo dos apetites os mais terríveis e à margem da lei, sua alma está entregue ao governo do gênero apetitivo. Em oposição a esse, encontra-se o paradigma da alma filosófica. O rei-filósofo é amigo do saber, em sua alma virtuosa governa o gênero racional em toda plenitude ${ }^{6}$ (capaz de contemplar o Ser e de governar-se), sendo o mais justo/dikaiótaton e, por isso, o mais feliz/eudaimonéstaton, rei de si mesmo/basileúonta autồ (580c).

Uma vida política existe dentro da psykhêe, assim como no interior da cidade, relações de poder que vão determinar condutas, no leque entre virtude e vício. A virtude da justiça (a unidade hierárquica entre elementos diferentes) está presente no paradigma da alma filosófica e está ausente naquele do tirano. Este é "escravo de si”, o mais injusto e infeliz, vive

\footnotetext{
${ }^{5}$ Ver no Timeu (42c-d; 86b-88b) sobre o estado de injustiça na alma como o de domínio das afecções e sobre as doenças que se constituem como desequilíbrio interno à alma e entre corpo e alma, assim como aquelas que dizem respeito à desproporção interna na alma e entre corpo e alma (86b-88b), o que analiso em Reis, 2007a, 2010.

${ }^{6}$ Tal caracterização dos regimes políticos e da alma de seus governantes encontra-se em República 445c-580c, passagens analisadas sob o foco da "teoria da tripartição da alma" em todo o item 4 de nossa dissertação, cf. Reis, 2000, 2009.
} 
uma morte psíquica, o pior estado possível de uma alma. Já quanto ao paradigma da alma filosófica, por ser virtuosa, essa é livre, autônoma. Ela possui seu melhor estado de alma e visa a "objetos" nobres. É importante reconhecermos em República IV-IX que os “objetos de amor" aos quais o rei-filósofo se dirige em relações de amizade (philía) são aqueles que se aproximam do inteligível, do maior grau de Ser. Pois há diferentes graus de Ser entre sensível e inteligível, como descritos no diagrama da linha (VI 509d-511e: imagens, seres animados, objetos matemáticos, formas inteligíveis) e no mito da caverna (VII 514a-520c: do visível ao inteligível, aqui destacando-se a forma do Bem). O rei-filósofo é amigo da sabedoria, da verdade, do imutável, das formas inteligíveis, do Bem em si. Ele não confunde o Bem com a opinião sobre o bem, com o poder, com os prazeres, pois ele os distingue do Bem em si (VI 505b-c; 520c-d). Ele diferencia várias espécies de prazer e escolhe prazeres com critério racional, ele visa sobretudo ao "prazer puro", que não gera dor, pois diz respeito ao inteligível, ao real.

O prazer daquele que se enche com as coisas que "são" menos (das espécies de coisas que se referem ao corpóreo) é referido por Platão como "menos verdadeiro". O prazer daquele que se enche com as coisas que "são" mais (das espécies de coisas que se referem à alma) é “o verdadeiro prazer", aquele que decorre da contemplação do inteligível pelo logistikón, aquele que se refere ao grau de Ser mais iluminado pela verdade (585b-e). Trata-se do prazer mais próprio (o mais agradável) dentre os demais prazeres, e isento de sofrimentos, o "prazer puro", inteligível, real; por isso ele é preferido pelo filósofo dentre as diversas espécies de prazer (586d-587a).

- Logo, seguindo toda a alma o filósofo/tôi philosóphōi e não se revoltando/stasiazoúsès contra nenhuma parte, é-lhe possível fazer as suas próprias coisas e estar em justiça/ dikaîoi eînai, e colher cada uma os prazeres que lhe são próprios, os de melhor qualidade e os mais verdadeiros possíveis. - Exatamente. - Mas quando domine um diferente, não lhe é dado encontrar o prazer que lhe é próprio, e de mais a mais, força a ir em busca de um prazer que lhes é alheio e que não é verdadeiro. (República 586e-587a)

Fácil é para a alma humana perder-se entre inúmeros prazeres possíveis. Para Platão, o caminho mais difícil, por isso mais belo, é criterioso e diz respeito a alcançar o limite máximo do aprimoramento da alma humana, a conquista da virtude, do inteligível, do prazer puro.

Vida é "estado de alma”, amizade à virtude. Na filosofia de Platão, a vida da alma é associada diretamente ao "estado de excelência" na alma, ao bom direcionamento de seus apetites, sentimentos e opiniões, estas devendo ser fundamentadas no saber inteligível. E um bom observador do texto de Platão percebe que esse percurso exige autoconhecimento. Sim, exige submeter-se à refutação, tomar consciência de si e do outro, de seus princípios constitutivos, bem como dos princípios que regem o cosmo e o que está "para além" dele. Nesse sentido, deve-se reconhecer que o "mito da caverna" possui significado ontológico, cognitivo e ético. Diferentes graus de Ser, diferentes graus de conhecimento humano, diferentes graus de ação ética dependendo do estado de conhecimento do Ser e de 
autoconhecimento que essa alma possui. O percurso de educação da alma pela dialética exige colocar em dúvida as próprias opiniões, sentimentos, impulsos, desejos, ações, crenças, refutar e ser refutado, reconhecer diferenças e relações de mediação dentro e fora de si mesmo, nos âmbitos da alma humana, da vida política e do que está para além da espaço-temporalidade sensível. Esse último ponto encontra-se mais detalhado na (também) narrativa mítica do Timeu. Trata-se dos princípios que independem da espaço-temporalidade do cosmo (instituída pela alma cósmica): as causalidades inteligente e errante, o nôus demiúrgico, as próprias Ideias/ formas inteligíveis. ${ }^{7}$ Dado que aquilo que é inteligível é um modo de ser distinto do sensível, mas em interrelação com ele pela mediação do modo de ser intermediário, característico da alma cósmica (Timen 35a-35b; 36d-37c), reconhecer tais relações de mediação é sinônimo de sabedoria e de conquista do melhor estado de alma possível para o ser humano. Sabemos bem que as narrativas míticas que Platão constrói para melhor falar sobre a educação da alma humana trazem um significado profundo sobre esse percurso e suas interrelações.

Quanto ao estado de morte psíquica, ele é assim caracterizado não apenas na análise da República sobre a alma tirânica, como no texto das Leis. Platão caracteriza como "escravidão cruel" o estado de alma daqueles que recebem uma educação de rigor extremo e rude (Leis VII 791d5-10) e como "viciosos e maus" aqueles que praticam ações deliberadamente e consentidamente más (IX 860e, 861e-862d; 874e). A alma destes vive um estado de morte de si mesma, pois se encontra presa ao prazer de praticar atos que satisfaçam a demandas de uma configuração injusta e má do todo de tal alma. Para o conhecimento do que Platão teria afirmado a respeito da morte, portanto, o leitor de sua obra não precisa se ater aos mitos do destino das almas presentes em diálogos como o Fédon, o Fedro, a República X. ${ }^{8}$ Independentemente de tais narrativas míticas acerca da alma post mortem, bem como das argumentações do Sócrates do Fédon a respeito da imortalidade da alma, ou mesmo da afirmação de um "princípio imortal" da alma humana postulado no Timeu (41c-d; 90a-c), o "estado de morte" humana oposto ao "estado de vida" é demonstrado e enfatizado nas argumentações sobre o indivíduo e a cidade, no decorrer de diálogos significativos como República e Leis. Nas considerações de ambos acerca da unidade triádica da psykkế do homem vivo, dependendo de sua educação e das relações de poder estabelecidas entre os três gêneros da alma, vai configurar-se na psykhế humana um estado de virtude, análogo à vida, ou um estado de ausência de virtude, o vício, análogo à morte psíquica.

Nas Leis, o Estrangeiro de Atenas, Clínias e Megilo discutem a respeito das constituições políticas vigentes e qual seria a melhor legislação para uma cidade, uma

\footnotetext{
${ }^{7}$ No âmbito das narrativas míticas do Fedro e do Timeu, Platão menciona realidades incorpóreas como existentes independentemente do âmbito espaço-temporal do céu (tà éxo tôิ ouranồ; Fedro 247c1; tòn huperouránion tópon; Fedro 247c3), Ideias/formas inteligíveis a serem rememoradas pela alma, igualmente incorpórea (Timen 34b3-4; 36e6; 46d). Trata-se de entes os mais iluminados pela verdade e que subsistem em si mesmos, ou seja, a sua existência independe da mente humana, bem como do todo espaço-temporal do cosmo (o tempo nasce "com" o céu pela ordenação do corpo do cosmo, promovida pela alma cósmica, Тimeu 37d; 37e; 28b3).

${ }^{8}$ Narrativas míticas que analisamos em Reis, 2003.
} 
constituição política voltada para a paz. Nesse projeto legislativo-político encontra-se também uma articulação profunda entre psicologia, ética e política. ${ }^{9}$ No presente artigo, ressalto apenas uma das retomadas da teoria da tripartição da alma, já desenvolvida na República, em Leis IX, quando Clínias pede para ouvir "uma exposição mais clara sobre a diferença entre injustiça e dano e os múltiplos aspectos que neles tomam o consentido e o inconsentido" (863a3-a6). Para responder a Clínias, o Estrangeiro de Atenas falará da natureza dos três gêneros da alma e, no interior desses, o que configuraria as "três causas de nossas faltas", ${ }^{10}$ a ignorância, a ira ou ânimo, o prazer. Como se segue:

At: - É preciso então tentar vos obedecer e falar. Evidentemente, em vossas audições e conversas mútuas, vós tomais a respeito da natureza da alma, ao menos, que uma de suas afecções (páthos) ou partes (méros), o ânimo (thymós), é uma propriedade tanto conflitante como combativa e que transtorna tudo por sua violência irracional (alogístöi bíâi). Cl: - Como não? (863a7-b5)

At: - Ora, distinguimos o prazer (hèdonén) do ânimo e afirmamos que o poder de domínio dele é de um tipo oposto, visto que pela persuasão, com um engano violento (metà apátés biaíou), pratica tudo que é desejado pelo seu querer (boúlèsis). Cl: - Exatamente. At: - Não seria errôneo dizer que a terceira causa de nossas faltas é a ignorância (ágnoian). Esta causa, todavia, o legislador faria bem em subdividir em duas... (Leis 863b6-c3).

O homem cujas partes da alma não foram educadas devidamente será movido por essas carências, dominado por alguma dessas três causas de nossas faltas. Agirá em função delas e não conforme o melhor para a sua própria alma como um todo e para aquela dos demais (para a cidade), encontrando-se em estado de injustiça interna (863e5-864a8; 864a8c9). Situação já retratada na imagem da marionete exposta no livro II das Leis, que mostra diferentes forças atuando em nós (os fios flexíveis), algumas em sentidos opostos. Conforme a essa imagem, a virtude depende da prevalência do "fio de ouro" da lei, ou seja, da vitória da razão nesse combate. ${ }^{11} \mathrm{E}$ para isso, é preciso resistir, como os soldados do livro I, não só aos sofrimentos, mas também a certos prazeres e, como os criminosos do livro IX, não só à violência do thymós e à sedução do apetitivo, mas também às ilusões de sabedoria.

\footnotetext{
${ }^{9}$ Articulação que foi objeto de análise em Reis, 2007; 2010.

${ }^{10}$ Cf. Leis 863a7-863e4; 863e5-864c8, passagens que tratam dessas três causas.

${ }^{11}$ A imagem (Leis 644c-645c) retrata os seres vivos / zóon como marionetes dos deuses, cujo propósito é ignorado pelos homens, guiados por "filos" de diversas espécies, que são as afecções /páthè (como o prazer e o sofrimento, o medo e a confiança, indicados em 644c-d). Essas afecções o enredam e, se são contrárias umas às outras, o arrastam para ações contrárias, "sob a linha divisória entre a virtude e o vício" (644e), pois, seguindo algumas afecções e resistindo a outras, encontra-se o fio condutor / agoggé sagrado do raciocínio / logismồ (ou "lei comum da cidade"), com o qual se deve colaborar "para assegurar que a raça áurea dentro de nós possa derrotar as outras raças” (645b).
} 
Mas nem todo homem cuja alma encontra-se em estado de injustiça é mau e passível de receber da legislação uma penalidade capaz de curar tal "estado de alma". Uma análise detalhada do livro IX das Leis permite inferir que, para Platão, o que evidencia ser má uma alma injusta não é o estado injusto de sua alma, mas o seu modo de agir, isto é, o fato de se tratar de uma ação consentidamente má, tendo ela gerado ou não algum dano a outrem. ${ }^{12}$ Por isso, para Platão, o que há de duplo e que deve ser considerado por aqueles que vão formular penalidades e correções através da lei é o caráter / êthos e modo de agir / trópos humanos (861e-862c4).

A educação filosófica, que na República era dirigida aos guardiões mais aptos ao exercício filosófico, nas Leis será reservada àqueles que compõem o Conselho Noturno ${ }^{13}$, comparados à alma ou intelecto / noûs da cidade (632c, 961d, 964e, 969b) e que terão a tarefa de preservar o respeito às leis e sua adequação à promoção da virtude, por serem guiados pela virtude do discernimento /phrónésis e pela opinião verdadeira / alethès dóxa (632c3-7). Eles instruirão os membros mais jovens do próprio Conselho, além dos jovens futuros governantes, bem como cuidarão da alma daqueles que necessitam ser persuadidos por argumentos. Os legisladores devem ter conhecimento a respeito da alma humana, formulando leis que misturem a persuasão / peithôi e a coação / bíai (722b6), com a finalidade de curar a parte da alma que esteja a conduzir a ação criminosa, bem como de imprimir razão, ordem, harmonia, virtude, paz, amizade nas relações dos indivíduos entre si, destes com a cidade e com as demais "coisas sagradas".

Agir de modo mau - ou bom - é resultado da interação em unidade das três partes da psykhé. As ações resultam da formação do "caráter", tal como o Estrangeiro nomeia em Leis IX 859d, ao tratar do caráter e do modo de agir injusto, bem como no livro VII 791cd, quando estabelece a educação da criança como a educação para uma boa disposição da alma / eupsykhias e do caráter (791c9-d10). A estruturação interna que a alma triádica possui, o caráter (bem formado ou não), leva ao modo de agir justo ou injusto. $\mathrm{O}$ vício e a virtude constituem "estados da alma" como um todo.

\section{Considerações FinAis}

Destacam-se, na filosofia platônica, as concepções de virtude e vício, vida e morte "na" psykhè,, como "estados de alma" conquistados segundo o grau de educação e amizade dos três gêneros da alma (tò logistikón, tò thymoeidés, tò epithymétikón), de autoconhecimento e conhecimento dos diferentes graus de Ser. Tal leitura reafirma a defesa de nossa tese de doutoramento que aponta a teoria da alma triádica, presente sobretudo nos diálogos República e Leis, como base da teoria ético-política de Platão.

\footnotetext{
${ }^{12}$ Nos capítulos III e IV de Reis, 2007a; 2010, encontra-se a referida análise da argumentação sobre ato consentido e ato inconsentido, bem como a defesa de que há, em Leis IX, uma mudança do pressuposto ético socrático do mal inconsentido, pois aquele que pratica o mal, o caráter e modo de agir injusto e mau, ele o faz consentidamente.

${ }^{13}$ Cf. Leis 818a-b, 908a-909a, 968d-e, 961a-b, 963a, 968b.
} 
A morte "na" alma configura-se como um estado de ausência de excelência da psykhé humana. Corresponde à escravidão de si próprio, ao predomínio, na alma, da amizade a ganhos, a certos prazeres, ao poder, bem como a um estado cognitivo de engano, como se eles fosse o bem "em si", "a verdade".

Em oposição a esse estado, encontra-se o paradigma da alma virtuosa, conquista árdua, graças à formação e educação da unidade "corpo-alma", dos três gêneros da psykhé em sua unidade dinâmica. O autoconhecimento e a devida educação da unidade "corpoalma" são necessários para a posse de uma estruturação virtuosa. A alma virtuosa é capaz de promover unidade e amizade na diferença, uma relação política justa, uma interrelação harmônica entre as três partes da alma, sob o governo do gênero racional. A vida "na" alma configura-se como o "estado de alma" mais excelente possível para um ser humano.

Só a alma virtuosa exerce plenamente as suas potencialidades, encontra-se no seu melhor estado, melhor para si mesma e para a cidade, ou seja, para o outro. Uma alma virtuosa não usa o outro para satisfazer demandas irracionais, mas conduz o outro também à busca da verdade, da virtude, do bem e do belo. A alma virtuosa exerce plenamente sua vitalidade, sua condição de liberdade, seu autodomínio. A alma é arkhế, princípio de geração e movimento, bem sabemos do Fedro. Mas sua estruturação pode caminhar de um leque a outro, do vício à virtude, da morte à vida, como atesta-se na República e nas Leis.

Assim reencontro a alma de nosso mestre, Marcelo Marques. Nas afirmativas de Platão. Suas ações e produções revelam o seu caráter, o de uma psyłkhé virtuosa. Ele não se reconheceria como tal, mas, certamente, como "amigo da virtude". Não é o caso, nesse momento, de debatermos sobre as considerações de Platão acerca da psykhé após a morte do corpo. Não é necessário.

Gêneros distintos da alma, justos: amigos. Partes da cidade, justas: amigas. Indivíduos entre si diante da lei: amigos. Nas passagens que apreciamos aqui, o significado de amizade em Platão diz respeito a uma relação de comunhão possível entre elementos diferentes. E só mesmo uma alma que tem em alto valor e prática a amizade, como a de Marcelo, pode (como um bom juiz) promover relações de comunhão e unidade, como as que estamos vivenciando nesse Simpósio. Aquele que contempla a virtude, assemelha-se ao contemplado.

Encerro essas considerações com uma passagem do Timeu que reafirma que a formação e a educação corretas da alma através da contemplação da ordem do todo, a busca de satisfação do apetite de discernimento, o cultivo à ciência, a pensamentos verdadeiros, às coisas imortais e divinas constitui o caminho para a conquista da virtude na alma, que passa a se assemelhar ao contemplado:

São eles que cada um deve seguir: os períodos relativos ao devir que têm lugar em nossa cabeça e que foram corrompidos, endireitando pelo aprendizado do todo, tanto harmonias como períodos. Aquele que contempla se assemelha, conforme a natureza original (arkhaían physin) ao contemplado e, tendo se assemelhado, finalmente ele possui (ékhein) a melhor vida preestabelecida tanto para o presente como para o tempo em seguida à vida. (Timen $90 \mathrm{a}-\mathrm{c}$, grifo nosso). 
Feito esse elogio, à vida de sua alma, e essa breve homenagem, resta-nos seguir o seu legado, sua vida e sua obra. E resta a mim, particularmente, desejar que, quando chegar a minha vez, "continuemos essa conversa".

\section{REFERÊNCIAS}

\section{FONTES PRIMÁRIAS}

PLATON. Phédon. Trad. Monique Dixsaut. Paris: GF-Flammarion, 1991.

PLATON. Phédre. Trad. Luc Brisson. Paris: GF-Flammarion, 1989.

PLATON. Phédre. Collection des Universités de France. Trad. L. Robin. Paris: Les Belles Lettres, 1947.

PLATON. La République. Trad. P. Pachet. Paris: Gallimard, 1993.

PLATON. Les Lois. Collection des Universités de France. Trad et com. A. Diés. Tome XI et XII. C.U.F. Paris: Les Belles Lettres, 1956.

PLATON. Les Lois. Trad. et com. Luc Brisson et Jean-François Pradeau. I-II. Paris: GFFlammarion, 2006.

PLATON. Timée/Critias. Trad. et com. Luc Brisson. Paris: GF-Flammarion, 1992.

PLATON. Timée. Collection des Universités de France. Trad. et com. Albert Rivauld. Tome X. C.U.F. Paris: Les Belles Lettres, 1956.

PLATÓN. Diálogos VIII-IX. Leyes. Trad. y com. Francisco Lisi. Madrid: Ed. Gredos, 1999.

PLATONIS Opera. T. IV tetralogiam VIII continens [Clitopho, Respublica, Timaevs et Critia], recognovit brevique adnotatione critica instruxit Ioannes Burnet. Oxford: Oxford Clarendon Press, 1902.

PLATÃO. República. Trad. M. H. da Rocha Pereira. 7. ed. Lisboa: Fundação Calouste Gulbenkian, 1993.

PLATÃO. Timeu. Trad. C. A. Nunes. Belém: Ed. Universidade Federal do Pará, 1986.

PLATÃO. As Leis. Trad. Edson Bini. Bauru, SP: EDIPRO, 1999.

\section{FONTES SECUNDÁRIAS}

BRÈS, Y. La psychologie de Platon. Paris: Presses Universitaires de France, 1968.

BRISSON, L. Le corps animal comme signe de la valeur d'une âme chez Platon. Animal (L') dans l'Antiquitè (congrès), 1997. p. 227-245.

CANTO-SPERBER, M. Les paradoxes de la vertu - Remarques sur la philosophie morale de Platon. Problèmes de la Morale Antique. Paris: Université d’Amiens, 1993. p. 59-74. 
COOPER, J. La théorie platonicienne de la motivation humaine. Trad. M. Canto-Sperber et L. Brisson. Revue philosophique, Paris, v. 4, p. 517-543, 1991.

DIXSAUT, M. Le Naturel philosophe: essai sur les dialogues de Platon. 2. ed. Paris: Vrin-Les Belles Lettres, 1994.

DYBIKOWSKI, J. C. Critical notice of T. M. Robinson, Plato's psychology. Canadian Journal of Philosophy, Alberta, v. 3, p. 131-142, 1973.

FRÈRE, Jean. Les Grecs et le Désir de L'Être: des Préplatoniciens à Aristote. Paris: Les Belles Lettres, 1981.

FRIAS, Ivan. A relação corpo-alma no Timen em função do binômio saúde-doença. Cadernos de Atas da ANPOF, Rio de Janeiro, v. 1, p.111-116, 2001.

FRIAS, Ivan. Doença do Corpo, Doença da Alma: Medicina e Filosofia na Grécia Clássica. São Paulo: Loyola, 2005.

GILL, C. Plato and the education of character. Archiv Für Geschichte der Philosophie, Berlin, v. 67, p. 1-26, 1985.

KONSTAN, David. A amizade no mundo clássico. Tradução de Márcia Epstein Fiker. São Paulo: Odysseus Editora, 2005.

LAURENT, Jérôme. L'éducation et l'enfance dans les Lois. Revue Pbilosophique de la France et de l'Étranger, Paris, p. 41-56, 2000.

LISI, Francisco. Les Fondements Philosophiques du nomos dans les Lois. Revue Pbilosophique de la France et de l'Étranger, Paris, v. 1, p. 57-82, 2000.

LISI, Francisco. A alma do mundo e a alma humana no Timeu. Apontamentos para uma reinterpretação da psicologia platônica. Trad. André Yasbek. Hypnos, São Paulo, v. 10, n. 14, p. 57-69, 2005.

MARQUES, M. P. Phantasia chez Platon. In: VEGLERIS, E. (Ed.). Cosmos et Psychè. Mèlanges offerts à Jean Frère. Hildesheim: Georg Olms Verlag, 2005. p.123-141.

MARQUES, M. P. Platão, pensador da diferença. Uma leitura do Sofista. Belo Horizonte: Editora UFMG, 2006. (Coleção Humanitas)

MÜLLER, Robert. La Doctrine Platonicienne de la Liberté. Histoire des Doctrines de L'Antiquité Classique, XXI. Jean Pépin (Dir.). Paris: J. Vrin, 1997.

REALE, G. Corpo, Alma e Saúde: o Conceito de Homem de Homero a Platão. Trad. Marcelo Perine. São Paulo: Paulus, 2002.

REIS, M. D. Um olhar sobre a psykhée : o logistikón como condição para a ação justa nos livros IV e IX da República de Platão. 2000. Dissertação (Mestrado em Filosofia) - Programa de Pós-Graduação em Filosofia, FAFICH/UFMG, Belo Horizonte, 2000. 
REIS, M. D. Sobre os mitos do destino das almas em Platão. Scripta Classica On-line, Belo Horizonte, n.1, abril de 2003. 21p.

REIS, M. D. Tripartição e unidade da psykehé no Timeu e nas Leis de Platão. 2007. Tese (Doutorado em Filosofia) - Programa de Pós-Graduação em Filosofia, FAFICH/UFMG, Belo Horizonte, 2007a. 304 p.

REIS, M. D. Por uma nova interpretação das doutrinas escritas: a filosofia de Platão é triádica. Kriterion Revista de Filosofia, Belo Horizonte, v. XLVIII, n. 116, p. 285-540, jul.-dez. 2007. p. 379-398, 2007b.

REIS, M. D. Psicologia, Ética e Politica: a tripartição da psykhé na República de Platão. São Paulo: Edições Loyola, 2009. 175p. (Coleção FAJE)

REIS, M. D. Virtude e Vício: tripartição e unidade da psykhé no Timeu e nas Leis de Platão. Rio de Janeiro: Ed. 7Letras, 2010. 272p.

RIST, J. M. Plato says that we have tripartite souls. If he is right, what can we do about it? In: Sophies Maietores (Chercheur de Sagesse), Mélanges J. Pépin. Paris: Institut d'Etudes Augustiniennes, p. 103-124, 1992.

ROBERTS, Jean. Plato on the causes of wrongdoing in the Laws. Ancient Philosophy, Pittsburg, v. 7, p. 23-37, 1987.

ROBINSON, Thomas. A Psicologia de Platão. Tradução de Marcelo Pimenta Marques. São Paulo: Edições Loyola, 2009.

SAUNDERS, T. J. The structure of the soul and the state in Plato's Laws. Eranos, v. 60, p. 37-55, 1962.

SCHILLER, J. Just men and just acts in Plato's Republic. Journal of the History of Philosophy, Berkeley, v. 6, p. 1-14, 1968.

SMITH, Nicholas D. Plato's analogy of soul and state. The Journal of Ethics. An international philosophical review, Dordrech, Hollande, v. 3, p. 31-49, 1999.

STALLEY, R. F. Plato's doctrine of freedom. Proceedings of the Aristotelian Society, Oxford [UK], v. 98, p.145-158, 1998.

STEEL, C. The Moral Purpose of the Human Body. A Reading of Timaeus 69-72. Phronesis, Koninklijke Brill N.V., Leiden, XLVI, 2: p. 105-128, 2001.

STOCKS, J. L. Plato and the tripartite soul. Mind, Oxford, v. 24, p. 207-221, 1915.

TEIXEIRA, E. F. B. A Educação do Homem segundo Platão. (Col. Filosofia). São Paulo: Paulus, 1999.

VARGAS, A. Tres partes del alma en la República. Dianoia, Universidad Autónoma Metropolitana Iztapalapa, v. 37, p. 37-47, 1991. 
VAZ, H. C. Lima. Antropologia Filosófica. V.I. São Paulo: Loyola, 1991.

VAZ, H. C. Lima. Escritos de Filosofia IV - Introdução à Ética Filosófica 1. São Paulo: Loyola, 1999.

WAGNER, Ellen (Dir.). Essays on Plato's Psychology. Lanham; Boulder; New York; Oxford: Lexington Books, 2001.

WOOD, Mary Hay. Plato's psychology in its bearing on the development of will. Mind, Oxford, v. 17, p. 193-213, 1908.

WOODS, Michael. Plato's division of the soul. Proceedings of the British Academy, v. 73, p.23$48,1987$. 